\title{
Effects of stromal cell-derived factor-1 and survivin gene polymorphisms on gastric cancer risk
}

\author{
EMMANOUIL LIARMAKOPOULOS ${ }^{1}$, GEORGE THEODOROPOULOS ${ }^{2}$, ANNA VAIOPOULOU ${ }^{3}$, SPYROS RIZOS $^{1}$, \\ GERASIMOS ARAVANTINOS $^{4}$, GREGORY KOURAKLIS ${ }^{5}$, NIKOLAOS NIKITEAS $^{5}$ and MARIA GAZOULI ${ }^{3}$ \\ ${ }^{1}$ First Surgical Department, Tzaneion Hospital, Piraeus; ${ }^{2}$ First Propaedeutic Surgical Department, \\ Hippocration University Hospital; ${ }^{3}$ Laboratory of Biology, School of Medicine, University of Athens; \\ ${ }^{4}$ Third Clinic of Pathology-Oncology, Agioi Anargyroi Oncology Hospital; \\ ${ }^{5}$ Second Propaedeutic Surgical Department, Laiko University Hospital, Athens, Greece
}

Received July 24, 2012; Accepted November 7, 2012

DOI: $10.3892 / \mathrm{mmr} .2012 .1247$

\begin{abstract}
Stromal-cell derived factor-1 (SDF-1), a CXC chemokine, is important for growth, angiogenesis and metastasis of tumor cells. The SDF1-3'A polymorphism has been investigated in various types of cancer; however, no information is currently available on its role in gastric cancer. Survivin is a member of the inhibitor of apoptosis family of proteins and has a genetic polymorphism $(-31 \mathrm{G} / \mathrm{C})$ located in the CDE/ $\mathrm{CHR}$ repressor element of its promoter. In this study, 88 gastric cancer patients and 480 normal healthy control subjects were investigated for the genotype and allelic SDF1-3'A and survivin $-31 \mathrm{G} / \mathrm{C}$ frequencies using polymerase chain reaction-restriction fragment length polymorphism. The SDF1-3'A genotype frequencies for GG, GA and AA were 44.32, 48.86 and $6.92 \%$ in patients and $42.71,47.71$ and $9.58 \%$ in healthy subjects, respectively. GA+AA genotype frequency and A allele distribution were not identified as significantly different between gastric cancer cases and controls. The survivin frequencies for GG, GC and CC were $20.45,50$ and $29.54 \%$ in patients and $33.96,45$ and $21.04 \%$ in healthy subjects, respectively. The $\mathrm{C}$ carriers ( $\mathrm{GC}+\mathrm{CC}$ genotype) and the $\mathrm{C}$ allele were over-represented among the gastric cancer cases $(\mathrm{P}=0.013$ and $\mathrm{P}=0.0083$, respectively). Overall, no statistically significant association was identified for SDF-1 and survivin gene examined alleles and genotypes and any parameter investigated, (e.g., stage, differentiation status and survival). The survivin promoter -31G/C polymorphism may confer an increased susceptibility to gastric cancer, while the SDF1-3'A polymorphism may not be a candidate genetic variant to select individuals at higher risk of developing gastric cancer.
\end{abstract}

Correspondence to: Dr Maria Gazouli, Laboratory of Biology, School of Medicine, University of Athens, Michalakopoulou 176, Athens 11527, Greece

E-mail:mgazouli@med.uoa.gr

Key words: gastric cancer, SDF-1, survivin, single nucleotide polymorphisms

\section{Introduction}

Gastric cancer is the fourth most common cancer and the second most frequent cause of mortality in the world. The prognosis is poor, with a five-year survival rate below $30 \%(1,2)$. Carcinogenesis of gastric cancer is a complex and multifactorial process, in which genetic and environmental factors are involved $(3,4)$. Marked racial and geographic differences in gastric cancer incidence may be also due to polymorphisms of genes being involved in various steps of carcinogenesis and implicated in gastric cancer susceptibility $(5,6)$.

Stromal cell-derived factor-1 (SDF-1), also known as CXCL12, is a chemokine acting as a growth factor for B-cell progenitors and a chemotactic factor for $\mathrm{T}$ cells and monocytes (7-9). SDF-1 binds to the CXCR4 receptor, resulting in a SDF-1/CXCR4 receptor-ligand system involving a one-on-one interaction $(10,11)$. The cytokine possesses angiogenic properties and mediates the dissemination of CXCR4-positive tumor cells to distant organs (12). SDF-1 promotes angiogenesis directly by binding to its receptors CXCR4 and/or CXCR7 expressed on endothelial cells or indirectly by the induced secretion of matrix-metalloproteases or angiogenic factors, respectively $(13,14)$. Furthermore, the SDF-1/CXCR4 axis is involved in tumor metastasis to sites which are characterized by high production of SDF-1, including liver, lung and bone marrow $(13,15)$. SDF-1 has three isoforms. The beta variant has a single nucleotide polymorphism $(\mathrm{G} \rightarrow \mathrm{A})$ at position 801 of the 3 -untranslated region of its gene (15-17). Allele A is a target for cis-acting factors, capable of upregulating expression of SDF-1 protein $(15,17,18)$. It was previously suggested that homozygotes for SDF1-3'A (3'A/3'A) express higher levels of SDF-1 compared with wild-type individuals $\left(3^{\prime} \mathrm{G} / 3^{\prime} \mathrm{G}\right)$. However, this observation requires additional confirmation $(15,19,20)$. The SDF-1 $\mathrm{G} \rightarrow \mathrm{A}$ polymorphism has been investigated in various types of cancer; however, limited information is currently available with respect to its role in gastric cancer (21-30). The first aim of our study was to explore the correlation between the SDF1-3'A polymorphism with the risk of gastric cancer development.

Survivin is a member of the inhibitors of apoptosis protein family, involved in regulation of apoptosis, cell cycle progres- 
sion and microtubule stability (30-34). Survivin contains a single baculovirus IAP repeat domain (35) and blocks death receptor and mitochondrial apoptosis pathways by directly inhibiting caspase- 3 and caspase- 7 and by interfering with caspase-9 activity/processing (36,37). Additionally, survivin counteracts apoptotic stimuli induced by interleukin 3, Fas, Bax, tumor necrosis factor $\alpha$, caspases, anticancer drugs and $\mathrm{X}$-rays $(38,39)$. It has been reported that survivin is associated with angiogenesis (40). Overexpression of survivin is frequently observed in various human malignancies, including colorectal cancer, lung cancer, hepatocellular carcinoma, pancreatic cancer and osteosarcoma (41-46). In addition, its overexpression is correlated with poor prognosis of those types of cancer.

Survivin is expressed in a cell-cycle-dependent manner. Expression levels peak in the G2/M phase of the cell cycle, when it is associated with microtubules of the mitotic spindle, followed by a rapid downregulation in the G1 phase (33). This is controlled at the transcriptional level and mediated by cell cycle-dependent elements (CDEs) and cell cycle homology regions (CHRs) located in the proximal region of the survivin promoter (47). Several single-nucleotide polymorphisms have been identified within the promoter region of the survivin gene, one of which is located at the CDE/CHR repressor binding site $(-31 \mathrm{G} / \mathrm{C})$. This polymorphism has been associated with overexpression of survivin and aberrant cell cycle-dependent transcription, mediated through the functional disruption of binding at the $\mathrm{CDE} / \mathrm{CHR}$ repressor motifs in a number of cancer cell lines (48). However, the $-31 \mathrm{G} / \mathrm{C}$ polymorphism within the $\mathrm{CDE} / \mathrm{CHR}$ repressor element of the promoter has not been extensively studied in human malignancies (49-51). Currently, the role of this polymorphism in gastric cancer is not fully understood. Therefore, based on these data, the second aim of the present study was to investigate whether the genetic polymorphism $-31 \mathrm{G} / \mathrm{C}$ located in the $\mathrm{CDE} / \mathrm{CHR}$ repressor element of the human survivin promoter is a risk factor for gastric cancer.

In the present study, we hypothesized that the aforementioned SDF-1 and survivin polymorphisms are associated with increased risk of gastric cancer and an aggressive tumor phenotype.

\section{Materials and methods}

Patients. The subjects in the hospital-based case-control were 88 unrelated gastric cancer patients (62 males and 26 females; mean age \pm SEM, $63.33 \pm 12.13$ years; median, 70 ; range, 27-82) with 480 ethnically, gender- and age-matched healthy control individuals (blood donors randomly selected from our DNA database) without evidence of malignancy or autoimmune disease. All patients and controls were born in and live in Greece. Informed consent was obtained from all patients and the hospital review board approved the study. According to the International Union Against Cancer classification and TNM staging system (54), 24 of the tumors (27.27\%) were stage I, $16(18.18 \%)$ stage II, 27 (30.68\%) stage III and $21(23.86 \%)$ stage IV (Table I). The patients were followed up until May 2012 or until mortality. The median time $( \pm \mathrm{SD})$ of follow-up was $36.27( \pm 19.5)$ months (range, 6-60 months). Follow-up was not performed for 17 patients as they could not be located.
Table I. Patient and tumor characteristics.

Characteristics

Gastric cancer patients

Age at diagnosis (years), mean $\pm \mathrm{SD}$

$63.33 \pm 12.13$

Male/female, $n$

$62 / 26$

Lymph node metastasis, $\mathrm{n}$

Negative

26

Positive

62

Other metastasis, $\mathrm{n}$

Negative

66

Positive

TNM stage at diagnosis, $\mathrm{n}$

I

II

16

III

27

IV

Tumor size $(\mathrm{cm}), \mathrm{n}$

$\leq 5$

40

$>5$

48

Lauren classification, $\mathrm{n}$

Intestinal

Diffuse

Determination of SDF-1 801G/A and survivin $-31 G / C$ polymorphism. Genomic DNA was isolated using a NucleoSpin Blood kit (Macherey-Nagel, GmbH \& Co. KG, Dueren, Germany) according to the manufacturer's instructions. Genotyping analysis was performed using polymerase chain reaction-restriction fragment length polymorphism for the polymorphisms. Primers used for SDF-1 genotyping were forward, 5'-CAGTCAACCTGGGCAAAGCC-3' and reverse, 5'-CCTGAGAGTCCTTTTGCGGG-3' (GenBank accession number L36033). The amplification included an initial denaturation at $94^{\circ} \mathrm{C}$ for $5 \mathrm{~min}$, followed by 35 cycles of denaturation at $94^{\circ} \mathrm{C}$ for $30 \mathrm{sec}$, annealing at $57^{\circ} \mathrm{C}$ for $90 \mathrm{sec}$ and extension at $72^{\circ} \mathrm{C}$ for $90 \mathrm{sec}$ and ended with a final elongation at $72^{\circ} \mathrm{C}$ for $5 \mathrm{~min}$. Amplicons of $293 \mathrm{bp}$ were subjected to restriction digestion by the HpaII enzyme. SDF-1 wild-type alleles yielded 100-and 193-bp products, while SDF-13'A alleles (polymorphic) yielded a 293-bp product. Primers used for survivin genotyping were forward, 5'-GTTCTTTGAAAGCAGTCGAG-3' and reverse, 5'-GCCAGTTCTTGAATGTAGAG-3'. The amplification included an initial denaturation at $94^{\circ} \mathrm{C}$ for $5 \mathrm{~min}$, followed by 35 cycles of denaturation at $94^{\circ} \mathrm{C}$ for $30 \mathrm{sec}$, annealing at $57^{\circ} \mathrm{C}$ for $90 \mathrm{sec}$ and extension at $72^{\circ} \mathrm{C}$ for $90 \mathrm{sec}$ and ended with a final elongation at $72^{\circ} \mathrm{C}$ for $5 \mathrm{~min}$. Amplicons of $341 \mathrm{bp}$ were then digested with the restriction enzyme EcoO109I (New England Biolabs Inc., Ipswich, MA, USA) at $37^{\circ} \mathrm{C}$ for $18 \mathrm{~h}$. The $\mathrm{G}$ allele was cleaved by the enzyme, generating two fragments (236 and $105 \mathrm{bp}$ ), whereas the $\mathrm{C}$ allele was not digested. Digestion patterns were analyzed by electrophoresis in a $2 \%$ agarose gel stained with ethidium bromide.

Statistical analysis. Statistical calculations were performed using the SPSS for Windows software package (SPSS Inc., 
Table II. Distribution of SDF1-3'A genotypes and alleles in patients and controls.

\begin{tabular}{lccc}
\hline Genotype/allele & Cases, $(\%, \mathrm{n}=88)$ & Controls, $\mathrm{n}(\%, \mathrm{n}=480)$ & P-value; OR (95\% CI) \\
\hline GG & $39(44.32)$ & $205(42.71)$ & Reference \\
GA & $43(48.86)$ & $229(47.71)$ & $1 ; 0.98(0.61-1.58)$ \\
AA & $6(6.82)$ & $46(9.58)$ & $0.52 ; 0.68(0.27-1.72)$ \\
GA+AA & $49(55.68)$ & $275(57.29)$ & $0.81 ; 0.94(0.59-1.48)$ \\
G & $121(68.75)$ & $639(66.56)$ & Reference \\
A & $55(31.25)$ & $321(33.44)$ & $0.6 ; 0.9(0.64-1.28)$ \\
\hline
\end{tabular}

OR, odds ratio; CI, confidence interval.

Table III. Distribution of survivin -31G/C genotypes and alleles in patients and controls.

\begin{tabular}{|c|c|c|c|}
\hline Genotype/allele & Cases, $\mathrm{n}(\%, \mathrm{n}=88)$ & Controls, $\mathrm{n}(\%, \mathrm{n}=480)$ & P-value; OR (95\% CI) \\
\hline GG & $18(20.45)$ & $163(33.96)$ & Reference \\
\hline GC & $44(50)$ & $216(45)$ & $0.05 ; 1.84(1.03-3.31)$ \\
\hline $\mathrm{CC}$ & $26(29.54)$ & $101(21.04)$ & $0.013 ; 2.33(1.22-4.47)$ \\
\hline $\mathrm{GC}+\mathrm{CC}$ & $70(79.54)$ & $317(66.04)$ & $0.013 ; 2(1.15-3.47)$ \\
\hline G & $80(45.45)$ & $542(56.46)$ & Reference \\
\hline $\mathrm{C}$ & $96(54.54)$ & $418(43.54)$ & $0.0083 ; 1.55(1.13-2.15)$ \\
\hline
\end{tabular}

OR, odds ratio; CI, confidence interval.

Chicago, IL, USA). Frequency and susceptibilities of mutations were compared using the $\chi^{2}$ test. Odds ratios (ORs) and 95\% confidence intervals (95\% CIs) were calculated using the corresponding $\chi^{2}$ distribution test. P-values obtained were two-tailed and $\mathrm{P}<0.05$ was considered to indicate a statistically significant difference. Hardy-Weinberg equilibrium was verified by calculating the expected frequencies and numbers and was tested separately in patients and in controls using the goodness-of-fit $\chi^{2}$ test.

\section{Results}

Tumor characteristics. Tumor characteristics are presented in Table I. The SDF-1 genotype and allele distribution among the 88 patients and 480 healthy controls is presented in Table II. The observed genotype frequencies were in accordance with Hardy-Weinberg equilibrium. Only 6 patients and 46 cases among the control group presented with the AA genotype. As a result, these were grouped together with the GA cases during the statistical analysis (Table II). The genotype frequencies for GG, GA and AA were 44.32, 48.86 and $6.82 \%$ in patients and $42.71,47.71$ and $9.58 \%$ in healthy subjects, respectively. GA+AA genotype frequency and A allele distribution were not identified as significantly different between gastric cancer cases and controls (Table II).

Survivin genotype and allele distribution. The survivin genotype and allele distribution among the 88 patients and 480 healthy controls is presented in Table III. The $-31 \mathrm{G} / \mathrm{C}$ genotype and allele distribution was identified as significantly different between gastric cancer cases and controls. The genotype frequencies for GG, GC and CC were 20.45, 50 and $29.54 \%$ in patients and $33.96,45$ and $21.04 \%$ in healthy subjects, respectively. GC+CC genotype frequency and $\mathrm{C}$ allele distribution were identified as significantly different between gastric cancer cases and controls. The $\mathrm{C}$ carriers $(\mathrm{GC}+\mathrm{CC}$ genotype) and the $\mathrm{C}$ allele were over-represented among the gastric cancer cases $(\mathrm{P}=0.013$ and $\mathrm{P}=0.0083$, respectively; Table III). With respect to the tumor characteristics, no statistically significant association was identified for SDF-1 and survivin examined alleles and genotypes and any parameter investigated (e.g., stage and differentiation status). A total of 19 mortalities occurred during the follow-up period and none of the alleles and genotypes conferred a survival advantage in this group of gastric cancer patients.

\section{Discussion}

It is commonly accepted that the clinical behavior of tumors depends on the interaction between tumor cells and the 'host'. The diverse cellular origins of SDF-1 and its constitutive expression in various organs warrant the study of this chemokine as an organ microenvironment 'host' factor in malignant and non-malignant pathologies (15-30). The majority of molecular studies have focused on mutational analysis of cancer-associated genes or carcinogen metabolizing genes; however, screening genetic polymorphisms of malignant stroma or microenvironment-related (i.e. SDF-1) and apoptosis (i.e. survivin) genes with the aim to uncover their potential predictive role must still be performed. In the present study 
we investigated the correlations between common genetic variants of SDF-1 and survivin promoter with gastric cancer risk and phenotypic aggressiveness in a cohort of patients of Greek descent. Although the polymorphisms of the two genes have been studied in several diseases and various other types of cancer, limited data are available with regard to the significance of the polymorphisms in gastric cancer.

Previous studies have demonstrated the oncogenic properties of the SDF-1 (CXCL12)/CXCR4 pathway $(12,21,28,29)$. In addition, the SDF-1/CXCR4 axis is a good candidate for chemical intervention, with the aim to generate a new therapeutic approach for various tumors (55). SDF-1/CXCR4 expression levels have been studied in gastric cancer; however, current literature is limited with respect to evaluation of the main genetic polymorphism of this molecule (i.e., SDF1-3'A) in this type of malignancy (56-59). For this reason, the elucidation of the potential role of this polymorphism in tumor development and potentially its progression is of great interest. The present results indicate that the SDF1-3'A polymorphism may not be a good candidate genetic variant to select human subjects at higher risk of developing gastric cancer. A correlation between adverse clinicopathological variables was not identified; however, the number of gastric cancer patients in the study was limited. Previous studies on colorectal cancer have also failed to identify a significant link between the SDF-1 polymorphism and the risk of colorectal cancer development $(28,29)$. However, the polymorphism has been previously associated with susceptibility to breast, lung, prostate and pancreatic cancer $(21,23,25-27,30)$. Extensive studies in breast cancer have demonstrated that the combination of low plasma SDF-1 levels and the SDF-1-3'A polymorphism may identify a cohort of patients with an intrinsic susceptibility for poorer survival (21). Variations in molecular mechanisms and modifications associated with the pathogenesis of various types of cancer may account for these diverse associations. Specifically, based on tissue origin, the effect of the SDF-1 gene polymorphism may contribute differentially to tumor progression, angiogenesis, metastasis and leukocyte migration.

According to the present results, no correlation has been identified among the typical progression markers, including histological grade, tumor size or metastatic profile. Nevertheless, the absence of an association of SDF1-3'A with gastric cancer risk and phenotype does not exclude the possibility that SDF-1 itself may affect cancer progression and aggression. It was previously reported that SDF-1 and CXCR4 expression in intestinal-type cancer is correlated with a significant increase in tumor size, depth of invasion and lymphatic and liver metastasis $(56,57)$. Serum SDF-1 levels were identified to be higher in patients with metastasis from gastric cancer, indicating that SDF-1 protein-expressing gastric cancer cells may be associated with tumor aggressiveness (58). In a previous study, CXCR4 was expressed in $50 \%$ of gastric cancer cases and was upregulated to a greater degree in gastric cancer than in normal gastric tissues. In addition a significant increase in SDF-1 mRNA in lymph nodes with cancer cell metastasis in comparison with normal lymph nodes was identified. The latter observation confirmed that cancer cells migrate towards an SDF-1 gradient established in specific target organs (59).

The mechanism behind the correlation between the SDF-1 polymorphism and clinical behavior of tumors, observed in a number of the single-nucleotide polymorphisms studied, remains under investigation. Alterations in SDF-1 gene functional levels, taking into consideration the biological role of this molecule in the tumor microenvironment and metastasis, may serve as a rational explanation. The mode of action of chemokines depends heavily on the local environment and the secreted SDF-1 produces a gradient for CXCRCR4-bearing cells $(30,59)$.

Survivin, a unique antiapoptotic factor, is involved in cell cycle regulation. Numerous clinical studies have demonstrated that survivin is markedly overexpressed in the majority of common types of cancer, indicating that transcriptional deregulation is a major mechanism associated with aberrant expression of survivin in cancer (42-48). In the present study, we investigated whether the $-31 \mathrm{G} / \mathrm{C}$ polymorphism in the survivin gene contributes to the development of gastric cancer. Previous studies have identified an elevated frequency of the $-31 \mathrm{C}$ allele in patients with lung, urothelial, renal, nasopharyngeal, thyroid, endometrial, esophageal and colorectal cancer. Consistent with these findings, the present results identified an association between the $-31 \mathrm{CC}$ genotype and the $-31 \mathrm{C}$ allele and a significantly increased risk of gastric cancer (50,60-69). However, Yang et al observed that the variant genotype (GG and GC) was associated with risk of distal gastric cancer or well-differentiated tumor. A statistically significant association was not identified between gastric cancer risk overall and variant genotype. However, the authors were in agreement with the hypothesis that the genotype is involved in distal gastric carcinogenesis and tumor differentiation in the Chinese population (52). By contrast, consistent with the present findings, Cheng et al demonstrated that the frequencies of survivin-31C allele and $\mathrm{C} / \mathrm{C}$ genotype were identified as significantly higher in gastric carcinoma patients than in healthy subjects, concluding that the $-31 \mathrm{C}$ genotype of the survivin promoter is a risk factor of gastric carcinoma (53). Li et al identified that $\mathrm{G}$ carriers of the survivin promoter gene may have an increased relative risk of developing gastric tumors of the diffuse type, localized in the antrum at a younger age. $C$ carriers with a high D17S250 microsatellite instability (TP53 gene) demonstrated an overall higher risk of developing gastric tumors, indicating that the mutated TP53 gene is unable to inhibit survivin expression, promoting gastric carcinogenesis (70). However, this polymorphism has yet to be identified as a risk marker in cervical, pancreatic and hepatocellular carcinomas $(49,51,71)$.

Although overexpression of survivin in human cancer types is a well accepted hypothesis, the differential role of its polymorphism remains to be understood. A rational explanation for this tumor-dependent difference in risk, conferred by the examined survivin polymorphism, may be attributed to differences in the carcinogenesis pathways among various types of human cancer. A number of studies have revealed that the survivin promoter $-31 \mathrm{G} / \mathrm{C}$ polymorphism may modulate the expression of survivin $(50,61,63)$. Due to its location at the $\mathrm{CDE} / \mathrm{CHR}$ repressor binding site, this polymorphism may affect the affinity of repressor binding to this region and the expression of survivin. Previously, an in vitro promoter assay revealed that the $-31 \mathrm{G}$ allele exhibited significantly lower transcriptional activity than the $-31 \mathrm{C}$ allele, indicating that the $-31 \mathrm{G} / \mathrm{C}$ polymorphism affects survivin expression and contributes to genetic susceptibility to lung cancer (50). In addition, 
the presence of the $-31 \mathrm{G} / \mathrm{C}$ polymorphism has been identified at higher frequencies in cancer cell lines and correlated with increased survivin expression at mRNA and protein levels (61). Since survivin functions as an inhibitor of apoptosis, a process important for the elimination of mutated or transformed cells from the body, it is possible that individuals carrying the higher production genotype of survivin $-31 \mathrm{G} / \mathrm{C}$ polymorphism may possess a decreased capacity to eliminate cells with DNA damage which may contribute to malignancies. Therefore, it is biologically plausible that the survivin promoter $-31 \mathrm{G} / \mathrm{C}$ polymorphism confers susceptibility to various types of cancer.

In conclusion, the present study comprised a homogeneous Greek population, in which it was identified that the survivin promoter -31G/C polymorphism confers an increased susceptibility to gastric cancer. This is an additional example of the role of apoptosis-related molecules in human malignancies. Owing to its association with poor prognosis and a global epidemiological distribution, gastric cancer remains at the forefront of contemporary epidemiological, basic and clinical research. Due to the small sample size of the present study, expansion of the study and inclusion of a higher number of patients is required. Well-designed and carefully executed multi-center studies, with enrollment of a large number of subjects, are predicted to reach more convincing and generalizable conclusions. Since genetic polymorphisms often exhibit ethnic differences, additional studies should include populations with diverse backgrounds to further elucidate the association of the examined polymorphisms with gastric cancer.

\section{Acknowledgements}

The present study was supported by the Hellenic Society for Medical Oncology (HESMO).

\section{References}

1. Ferlay J, Shin HR, Bray F, Forman D, Mathers C and Parkin DM: Estimates of worldwide burden of cancer in 2008: GLOBOCAN 2008. Int J Cancer 127: 2893-2917, 2010.

2. Noffsinger A and Waxman I: Preinvasive neoplasia in the stomach: diagnosis and treatment. Clin Gastroenterol Hepatol 9: 1018-1023, 2007

3. Resende C, Ristimäki A and Machado JC: Genetic and epigenetic alteration in gastric carcinogenesis. Helicobacter 1: 34-39, 2010.

4. Venkateshwari A, Krishnaveni D, Venugopal S, Shashikumar P, Vidyasagar A and Jyothy A: Helicobacter pylori infection in relation to gastric cancer progression. Indian J Cancer 48: 94-98, 2011.

5. Loh M, Koh KX, Yeo BH, et al: Meta-analysis of genetic polymorphisms and gastric cancer risk: variability in associations according to race. Eur J Cancer 45: 2562-2568, 2009.

6. Gao L, Nieters A and Brenner H: Cell proliferation-related genetic polymorphisms and gastric cancer risk: systematic review and meta-analysis. Eur J Hum Genet 17: 1658-1667, 2009.

7. Tashiro K, Tada H, Heilker R, Shirozu M, Nakano T and Honjo T: Signal sequence trap: a cloning strategy for secreted proteins and type I membrane proteins. Science 261: 600-603, 1993.

8. Nagasawa T, Kikutani H and Kishimoto T: Molecular cloning and structure of a pre-B-cell growth-stimulating factor. Proc Natl Acad Sci USA 91: 2305-2309, 1994.

9. Bleul CC, Fuhlbrigge RC, Casasnovas JM, Aiuti A and Springer TA: A highly efficacious lymphocyte chemoattractant, stromal cell-derived factor 1 (SDF-1). J Exp Med 184: 1101-1109, 1996.

10. Bleul CC, Farzan M, Choe H, et al: The lymphocyte chemoattractant SDF-1 is a ligand for LELESTR/fusin and blocks HIV-1 entry. Nature 382: 829-833, 1996.
11. Tachibana K, Hirota S, Iizasa H, et al: The chemokine receptor CXCRCR4 is essential for vascularization of the gastrointestinal tract. Nature 393: 591-594, 1998.

12. Vandercappellen J, Van Damme J and Struyf S: The role of CXC chemokines and their receptors in cancer. Cancer Lett 267: 226-244, 2008.

13. Kucia M, Reca R, Miekus K, et al: Trafficking of normal stem cells and metastasis of cancer stem cells involve similar mechanisms: pivotal role of the SDF-1-CXCR4 axis. Stem Cells 23: 879-894, 2005.

14. Zheng K, Li HY, Su XL, Wang XY, Tian T, Li F and Ren GS: Chemokine receptor CXCR7 regulates the invasion, angiogenesis and tumor growth of human hepatocellular carcinoma cells. J Exp Clin Cancer Res 29: 31, 2010.

15. Watanabe MA, de Oliveira Cavassin GG, Orellana MD, Milanezi CM, Voltarelli JC, Kashima S and Covas DT: SDF-1 gene polymorphisms and syncytia induction in Brazilian HIV-1 infected individuals. Microb Pathog 35: 31-34, 2003.

16. Dean M, Carrington M and O'Brien SJ: Balanced polymorphism selected by genetic versus infectious human disease. Annu Rev Genomics Hum Genet 3: 263-292, 2002.

17. Voevodin A, Samilchuk E and Dashti S: Frequencies of SDF-1 chemokine, CCRCCRCCR-5 and CCRCCRCCR-2 chemokine receptor gene alleles conferring resistance to human immunodeficiency virus type 1 and AIDS in Kuwaitis. J Med Virol 58: 54-58, 1999.

18. Winkler C, Modi W, Smith MW, et al: Genetic restriction of AIDS pathogenesis by an SDF-1 chemokine gene variant. ALIVE Study, Hemophilia Growth and Development Study (HGDS), Multicenter AIDS Cohort Study (MACS), Multicenter Hemophilia Cohort Study (MHCS), San Francisco City Cohort (SFCC). Science 279: 389-393, 1998.

19. Sei S, O'Neill DP, Stewart SK, et al: Increased level of stromal cell-derived factor-1 mRNA in peripheral blood mononuclear cells from children with AIDS-related lymphoma. Cancer Res 61: 5028-5037, 2001

20. Ide A, Kawasaki E, Abiru N et al: Stromal-cell derived factor-1 chemokine gene variant is associated with type 1 diabetes age at onset in Japanese population. Hum Immunol 64: 973-978, 2003.

21. Hassan S, Baccarelli A, Salvucci O and Basik M: Plasma stromal cell-derived factor-1: host derived marker predictive of distant metastasis in breast cancer. Clin Cancer Res 14: 446-454, 2008.

22. Khademi B, Razmkhah M, Erfani N, Gharagozloo M and Ghaderi A: SDF-1 and CCR5 genes polymorphism in patients with head and neck cancer. Pathol Oncol Res 14: 45-50, 2008.

23. Hirata H, Hinoda Y, Kikuno N, et al: CXCL12 G801A polymorphism is a risk factor for sporadic prostate cancer susceptibility. Clin Cancer Res 13: 5056-5062, 2007.

24. Nahon P, Sutton A, Rufat P, et al: Chemokine system polymorphisms, survival and hepatocellular carcinoma occurrence in patients with hepatitis C virus-related cirrhosis. World J Gastroenterol 14: 713-719, 2008.

25. Razmkhah M, Doroudchi M, Ghayumi SM, Erfani N and Ghaderi A: Stromal cell-derived factor-1 (SDF-1) gene and susceptibility of Iranian patients with lung cancer. Lung Cancer 49: 311-315, 2005.

26. Coelho A, Calcada C, Catarino R, Pinto D, Fonseca G and Medeiros R: CXCLCL12-3' A polymorphism and lung cancer metastases protection: new perspectives in immunotherapy? Cancer Immunol Immunother 55: 639-643, 2006.

27. Razmkhah M, Talei AR, Doroudchi M, Khalili-Azad T and Ghaderi A: Stromal cell-derived factor-1 (SDF-1) alleles and susceptibility to breast carcinoma. Cancer Lett 225: 261-266, 2005.

28. Dimberg J,Hugander A,Lofgren S and Wagsater D: Polymorphism and circulating levels of the chemokine CXCLCL12 in colorectal cancer patients. Int J Mol Med 19: 11-15, 2007.

29. Hidalgo-Pascual M, Galan JJ, Chaves-Conde M, et al: Analysis of CXCL12 3'UTR G>A polymorphism in colorectal cancer. Oncol Rep 18: 1583-1587, 2007.

30. Theodoropoulos GE, Panoussopoulos GS, Michalopoulos NV, et al: Analysis of the stromal cell-derived factor 1-3'A gene polymorphism in pancreatic cancer. Mol Med Report 3: 693-698, 2010.

31. Ambrosini G, Adida C and Alteri DC: A novel anti-apoptosis gene, survivin, expressed in cancer and lymphoma. Nat Med 3: 917-921, 1997.

32. Deveraux QL and Reed JC: IAP family proteins - suppressors of apoptosis. Genes Dev 13: 239-252, 1999.

33. Li F, Ambrosini G, Chu EY, et al: Control of apoptosis and mitotic spindle checkpoint by survivin. Nature 396: 580-584, 1998. 
34. Altieri DC: The molecular basis and potential role of survivin in cancer diagnosis and therapy. Trends Mol Med 7: 542-547, 2001.

35. Liston P, Fong WG and Korneluk RG: The inhibitors of apoptosis: there is more to life than $\mathrm{Bcl} 2$. Oncogene 22: 8568-8580, 2003

36. Thompson CB: Apoptosis is the pathogenesis and treatment of disease. Science 267: 1456-1462, 1995.

37. Raff M: Cell suicide for beginners. Nature 396: 119-122, 1998.

38. Tamm I, Wang Y, Sausville E, et al: IAP-family protein survivin inhibits caspase activity and apoptosis induced by Fas (CD95), Bax, caspases and anticancer drugs. Cancer Res 58: 5315-5320, 1998.

39. Asanuma K, Moriai R, Yajima T, et al: Survivin as a radioresistance factor in pancreatic cancer. Jpn J Cancer Res 91: 1204-1209, 2000.

40. Kawasaki H, Toyoda M, Shinohara H, et al: Expression of survivin correlates with apoptosis, proliferation and angiogenesis during human colorectal tumorigenesis. Cancer 91: 2026-2032, 2001.

41. Altieri DC: Survivin, cancer networks and pathway-directed drug discovery. Nat Rev Cancer 8: 61-70, 2008.

42. Chen WC, Liu Q, Fu JX and Kang SY: Expression of survivin and its significance in colorectal cancer. World J Gastroenterol 10: $2886-2889,2004$

43. Falleni M, Pellegrini C, Marchetti A, et al: Survivin gene expression in early-stage non-small cell lung cancer. J Pathol 200: 620-626, 2003.

44. Fields AC, Cotsonis G, Sexton D, Santoianni R and Cohen C: Survivin expression in hepatocellular carcinoma: correlation with proliferation, prognostic parameters and outcome. Mod Pathol 17: 1378-1385, 2004

45. Liu BB and Wang WH: Survivin and pancreatic cancer. World J Clin Oncol 2: 164-168, 2011.

46. Wang W, Luo $\mathrm{H}$ and Wang A: Expression of survivin and correlation with PCNA in osteosarcoma. J Surg Oncol 93: 578-584, 2006.

47. Altieri DC, Marchisio PC and Marchisio C: Survivin apoptosis: an interloper between cell death and cell proliferation in cancer. Lab Invest 79: 1327-1333, 1999.

48. Xu Y, Fang F, Ludewig G, Jones G and Jones D: A mutation found in the promoter region of the human survivin gene is correlated to overexpression of survivin in cancer cells. DNA Cell Biol 23: 527-537, 2004.

49. Borbély AA, Murvai M, Szarka K, et al: Survivin promoter polymorphism and cervical carcinogenesis. J Clin Pathol 60: 303-306, 2007

50. Jang JS, Kim KM, Kang KH, et al: Polymorphisms in the survivin gene and the risk of lung cancer. Lung Cancer 60: 31-39, 2008.

51. Theodoropoulos GE, Michalopoulos NV, Panoussopoulos SG, Taka S and Gazouli M: Effects of caspase-9 and survivin gene polymorphisms in pancreatic cancer risk and tumor characteristics. Pancreas 39: 976-980, 2010.

52. Yang L, Zhu H, Zhou B, et al: The association between the survivin $\mathrm{C}-31 \mathrm{G}$ polymorphism and gastric cancer risk in a Chinese population. Dig Dis Sci 54: 1021-1028, 2008.

53. Cheng ZJ, Hu LH and Huang SJ: Correlation of $-31 \mathrm{G} / \mathrm{C}$ polymorphisms of survivin promoter to tumorigenesis of gastric carcinoma. Ai Zheng 27: 258-263, 2008 (In Chinese).
54. Sobin LH and Wittekind C: UICC TNM Classification of Malignant Tumours. 5th edition, Wiley-Liss, New York, NY, 1997.

55. Juarez J, Bendall L and Bradstock K: Chemokines and their receptors as therapeutic targets: the role of the SDF-1/CXCR4 axis. Curr Pharm Res 10: 1245-1259, 2004.

56. Iwasa S, Yanagawa T, Fan J and Katoh R: Expression of CXCR4 and its ligand SDF-1 in intestinal-type gastric cancer is associated with lymph node and liver metastasis. Anticancer Res 29: 4751-4758, 2009.

57. Ishigami S, Natsugoe $\mathrm{S}$, Okumura $\mathrm{H}$, et al: Clinical implication of CXCL12 in gastric cancer. Ann Surg Oncol 14: 3154-3158, 2007.

58. Woo IS, Hong SH, Byun JH, Kang JH, Jeon HM and Choi MG: Circulating stromal cell derived factor- 1 is predictive of distant metastasis in gastric carcinoma. Cancer Invest 26: 256-261, 2008.

59. Zhao BC, Wang ZJ, Mao WZ, et al: CXCR4/SDF-1 axis is involved in lymph node metastasis of gastric carcinoma. World $\mathrm{J}$ Gastroenterol 17: 2389-2396, 2011.

60. Wang YH, Chiou HY, Lin CT, et al: Association between survivin gene promoter $-31 \mathrm{C} / \mathrm{G}$ polymorphism and urothelial carcinoma risk in Taiwanese population. Urology 73: 670-674, 2009.

61. Xu Y, Fang F, Ludewig G, et al: A mutation found in the promoter region of the human survivin gene is correlated to overexpression of survivin in cancer cells. DNA Cell Biol 23: 419-429, 2004.

62. Xang X, Xiong G, Chen X, et al: Polymorphisms of survivin promoter are associated with risk of esophageal squamous cell carcinoma. J Cancer Res Clin Oncol 135: 1341-1349, 2009.

63. Gazouli M, Tzanakis N, Rallis G, et al: Survivin -31G/C promoter polymorphism and sporadic colorectal cancer. Int J Colorectal Dis 24: 145-150, 2009.

64. Qin C, Cao Q, Li P, et al: Functional promoter $-31 \mathrm{G}>\mathrm{C}$ variant in survivin gene is associated with risk and progression of renal cell cancer in a Chinese population. PLoS One 7: e28829, 2012.

65. Yazdani N, Sayahpour FA, Haghpanah V, et al: Survivin gene polymorphism association with papillary thyroid carcinoma. Pathol Res Pract 208: 100-103, 2012.

66. Jaiswal PK, Goel A, Mandhani A and Mittal RD: Functional polymorphisms in promoter survivin gene and its association with susceptibility to bladder cancer in North Indian cohort. Mol Biol Rep 39: 5615-5621, 2012.

67. Zahedi P, Aminimoghaddam S, Sayahpour FA, et al: Association of survivin gene polymorphism with endometrial cancer. Int J Gynecol Cancer 22: 35-37, 2012.

68. Ma F, Zhang H, Zhai Y, et al: Functional polymorphism -31C/G in the promoter of BIRC5 gene and risk of nasopharyngeal carcinoma among chinese. PLoS One 6: e16748, 2011.

69. Upadhyay R, Khurana R, Kumar S, Ghoshal UC and Mittal B: Role of survivin gene promoter polymorphism $(-31 \mathrm{G}>\mathrm{C})$ in susceptibility and survival of esophageal cancer in northern India. Ann Surg Oncol 18: 880-887, 2011.

70. Li Y, Wang J, Jiang F, Lin W and Meng W: Association of polymorphisms in survivin gene with the risk of hepatocellular carcinoma in Chinese han population: a case control study. BMC Med Genet 13: 1, 2012.

71. Borges BN, Burbano RR and Harada ML: Survivin -31C/G polymorphism and gastric cancer risk in a Brazilian population. Clin Exp Med 11: 189-193, 2011. 